\title{
Editorial
}

Nephrology

\section{Vascular Access in the Elderly: Does One Size Fit All?}

\author{
Miten J. Dhruve Christopher T. Chan \\ Division of Nephrology, University Health Network, Toronto, ON, Canada
}

Given the major advances in dialysis practices and technology, the feasibility of offering renal replacement therapy to increasingly more challenging and complex patients is now possible. The elderly patient population that requires renal replacement is rapidly becoming the fastest growing subgroup of all patients with end-stage renal disease (ESRD) [1]. Although most consensus guidelines advocate the use of permanent vascular access for all patients with ESRD, given the limited life expectancy coupled with a relative high rate of primary malfunction, a pragmatic use of central venous catheters (CVCs) may be considered in the elderly. Raimann et al. [2], in this issue of American Journal of Nephrology present new data to assess important outcomes with relation to $\mathrm{CVC}$ vs. non-CVC in the elderly dialysis population ( $\geq 70$ years of age) using the MONDO study infrastructure.

This study specifically examined incident hemodialysis patients older than 70 years of age from the United States, Europe, Asia Pacific, and Latin America. The main aim of the study was to access the factors associated with conversion from CVC to non-CVC access and to ascertain an association between vascular access type and mortality. The cohort included 14,966 patients primarily from Europe and equally distributed among the 3 remaining geographical areas. CVC prevalence was noted to range from 32 to $69 \%$ and decreased in all regions after the first year of dialysis. North America had the highest prevalence of CVC by the end of the first year, while Asia Pacific showed the largest decrease in CVC prevalence at the end of year 1 . Younger (70-79 years) patients were more likely to convert to a non-CVC access as compared to those $\geq 80$ years old. After adjustment of several factors, this difference between the 2 age groups persisted with greatest significance in the European subpopulation. Furthermore, patients who were maintained on CVC as their primary vascular access had a higher risk of death compared to those who converted from CVC to AV graft (AVG) or AV fistula (AVF). The authors concluded that elderly patients who commenced HD with a CVC should be converted to a non-CVC access as soon as possible after taking into account their individual clinical risk assessment [2].

The present study extended the emerging body of published literature describing the association between CVC use and higher mortality rate even in the elderly subgroups. Pastan et al. [3] demonstrated that in a cohort of 7,497 patients, the proportion of deaths among those dialyzed with CVC was 3.2\% compared to non-CVC at less than $1.2 \%$. Similarly, Bradbury et al. [4] studied incident US hemodialysis patients in Dialysis Outcomes and Practice Patterns Study and observed that conversion of CVC access to an AVF or AVG resulted in an adjusted mortality hazard ratio (HR) of 0.69 , while conversion from permanent access to a catheter was associated with an adjusted mortality HR of 1.81. They also comment on the finding that most patients who converted were young, had more than 1 pre-dialysis permanent vascular access placement, and were less likely to have coronary, cerebrovascular, neurologic and peripheral vascular disease.

\section{KARGER}

(C) 2017 S. Karger AG, Basel

E-Mail karger@karger.com

www.karger.com/ajn
Dr. Christopher T. Chan

Division of Nephrology, University Health Network

200 Elizabeth Street, 8N Room 846

Toronto, ON M5G 2C4 (Canada)

E-Mail christopher.chan@uhn.ca 
Nonetheless, the present observation needs to be interpreted with caution. Given the retrospective observational design, there are innate selection and information biases. It is also important to take into account the reason(s) accounting for the inability to attain a non-CVC access. Factors such as burden of comorbid illnesses, patients' preferences, availability of pre-dialysis care, and amenability of vasculature for access formation may all lead to the initiation of hemodialysis using CVC access. These factors have also been linked with worse prognosis; hence, the putative causal link between CVC and worsening mortality rates may not be justified because of residual confounding.

Pragmatically, a universal recommendation for the use of non-CVC in all patients with ESRD must also require the balance between the success and failure of vascular access surgery. Several large studies and meta-analyses have shown that the primary and secondary patency rates for non-CVC access in the elderly population ( $\geq 60$ years) was approximately 50 and $65 \%$, respectively $[5,6]$. Richardson et al. [7] presented a retrospective review of access in 168 patients of whom 48 were older than 70 years of age. They reported a 12-month primary patency of 35\% and secondary patency of $36 \%$. Eighteen-month survival in the elderly group was $50 \%$ and average time to death was 13.1 months. They also noted that only 8 AVF in patients who died were ever accessed [7]. This begs the question of whether the morbidity and mortality risks of AVF/
AVG planning and insertion are worth the benefits in all octogenarians.

Octogenarians have a 1-year mortality rate of up to $50 \%$ driven mainly due to their comorbidities and frailty. For incident patients who have a very large comorbid burden and poor prognosis, a reasonable approach would be conservative care. This is an option that is fortunately being increasingly discussed with patients in order to provide them with dignity in their remaining time. Another equally reasonable approach would be offering dialysis as a therapy for symptom control in palliative patients whose symptoms are interfering with their quality of life. In this particular scenario, subjecting a patient to the surgical burden and risk may be inappropriate.

In conclusion, patients who initiate dialysis through CVCs have an increased mortality rate compared to nonCVC access. However, whether there is a need for a universal approach to non-CVC access adoption or an individualization of the risk and benefits for the appropriate vascular access planning in the elderly requires further prospective evaluation.

\section{Disclosure Statement}

Dr. Miten J. Dhruve is supported by the Baxter-UHN Home Dialysis Fellowship. Dr. Christopher T. Chan holds the R Fraser Elliott Chair in Home Dialysis. He consulted for Baxter, Intelomed, NxStage and Medtronic Inc.

\section{References}

1 Saran R, Robinson B, Abbott KC, Agodoa LY, Ayanian J, Bragg-Gresham J, et al: US renal data system 2016 annual data report: epidemiology of kidney disease in the United States. Am J Kidney Dis 2017;69(3S1):A7-A8.

2 Raimann JG, Barth C, Usvyat LA, Preciado P, Canaud B, Etter M, et al: Dialysis access as an area of improvement in elderly incident hemodialysis patients: results from a cohort study from the international monitoring dialysis outcomes initiative. Am J Nephrol 2017;45:486-496.
3 Pastan S, Soucie JM, McClellan WM: Vascular access and increased risk of death among hemodialysis patients. Kidney Int 2002;62: 620-626.

4 Bradbury BD, Chen F, Furniss A, Pisoni RL Keen M, Mapes D, et al: Conversion of vascular access type among incident hemodialysis patients: description and association with mortality. Am J Kidney Dis 2009;53:804814.

5 Al-Jaishi AA, Lok CE, Garg AX, Zhang JC, Moist LM: Vascular access creation before he- modialysis initiation and use: a populationbased cohort study. Clin J Am Soc Nephrol 2015;10:418-427.

6 Lok CE, Oliver MJ, Su J, Bhola C, Hannigan $\mathrm{N}$, Jassal SV: Arteriovenous fistula outcomes in the era of the elderly dialysis population. Kidney Int 2005;67:2462-2469.

7 Richardson AI 2nd, Leake A, Schmieder GC, Biuckians A, Stokes GK, Panneton JM, et al: Should fistulas really be first in the elderly patient? J Vasc Access 2009;10:199202. 